\title{
Resistance of Venturia inaequalis to demethylation inhibitor and dodine fungicides in four New Zealand apple-growing regions
}

\author{
R.M. Beresford ${ }^{1}$, P.J. Wright ${ }^{2}$, P.N. Wood ${ }^{3}$, N.M. Park ${ }^{3}$, N.J. Larsen ${ }^{1}$ and B.M. Fisher ${ }^{3}$ \\ ${ }^{1}$ The New Zealand Institute for Plant \& Food Research Ltd, Mt Albert Research Centre, \\ Private Bag 92169, Auckland 1142, New Zealand \\ ${ }^{2}$ The New Zealand Institute for Plant \& Food Research Limited, Cronin Road, RD1 \\ Pukekohe, New Zealand \\ ${ }^{3}$ The New Zealand Institute for Plant E Food Research Ltd, Hawke's Bay Research Centre, \\ Private Bag 1401, Havelock North, Hastings 4157, New Zealand \\ Corresponding author: robert.beresford@plantandfood.co.nz
}

\begin{abstract}
A survey of 41 apple orchards in Hawke's Bay (25), Nelson (7), Otago (4) and Waikato (5) provided 796 isolates of Venturia inaequalis (black spot or scab), which were tested using an agar plate assay for sensitivity to two demethylation inhibitor (DMI) fungicides (myclobutanil and penconazole) and to dodine. Each fungicide was used at two concentrations to distinguish between highly sensitive, sensitive and resistant isolates. Sensitivity to DMIs in all regions was lower than baseline sensitivity in previous studies, particularly for myclobutanil. Waikato showed significantly lower DMI sensitivity than other regions. Dodine sensitivity was greater than in the 1990s, although Otago isolates were significantly less dodine-sensitive than those from other regions. In a plant inoculation assay to test control by five DMI fungicides of disease caused by resistant isolates, flusilazol and difenoconazole gave significantly better disease control of resistant isolates than myclobutanil, penconazole or fenbuconazole, at standard field rates.
\end{abstract}

Keywords fungicide resistance, apple scab, demethylation inhibitor, dodine, resistance management.

\section{INTRODUCTION}

Fungicides with site-specific modes of action that are used in apple spray programmes for control of black spot (scab), caused by Venturia inaequalis, include demethylation inhibitor (DMI), dodine, quinone outside inhibitor (QoI) and anilopyrimidine (AP) groups. These fungicides are currently being investigated in relation to fungicide resistance development in $V$. inaequalis (Beresford et al. 2012; Viljanen-Rollinson et al. 2013; Larsen et al.2013; FRAC 2013). The potential impacts of resistance on the New Zealand apple industry include increased economic losses from increased incidence of black spot in orchards and threats to market access from diseased fruit and increased fungicide residues.

Current New Zealand DMI resistance management guidelines recommend a maximum of four DMI applications per season and mixing of each application with a fungicide from a different cross-resistance group (Beresford 
2005a). For dodine, resistance management guidelines recommend a maximum of three applications per season and avoidance of consecutive applications (Beresford 2005b).

A survey of Hawke's Bay apple orchards in the 2010-11 season (Beresford et al. 2012) indicated that DMI sensitivity in $V$. inaequalis had decreased since surveys in the 1990s (Whelan et al. 1992; Bakker et al. 1995), to a degree where loss of black spot control could now be expected in some orchards. There was no evidence of a loss of sensitivity to dodine in Hawke's Bay since the 1990s (Bakker et al. 1995; Bakker 1999).

The present study undertook a wider survey to determine the frequency of DMI and dodine resistance in all the main apple-growing regions of New Zealand. Of the five DMI active ingredients currently registered for use on apples in New Zealand, myclobutanil and penconazole were chosen for testing because they have been widely used and their sensitivity has previously been monitored, both in New Zealand and overseas. All five DMI active ingredients were also tested for their ability to control black spot caused by selected sensitive and resistant $V$. inaequalis isolates on potted apple trees.

\section{MATERIALS AND METHODS}

\section{Orchard sampling and $V$. inaequalis isolation}

Populations of about $20 \mathrm{~V}$. inaequalis isolates per orchard were obtained during December 2011 and January 2012 from apple fruit lesions from 41 orchard blocks (Table 1) in Hawke's Bay (25), Nelson (7), Otago (4) and Waikato (5). The cultivars sampled were 'Royal Gala' (35 blocks), 'Braeburn' (two blocks), 'Fuji' (two blocks) and Pink Lady ${ }^{\circledR}$ (two blocks). Venturia inaequalis conidia were scraped from the sporulating fruit lesions and streaked onto water agar. After $48 \mathrm{~h}$ of incubation at $20^{\circ} \mathrm{C}$, individual germinating conidia were isolated onto potato dextrose agar (PDA) amended with penicillin (100 mg/litre) and streptomycin sulphate (100 $\mathrm{mg} /$ litre) to inhibit bacteria. Colonies were incubated on a laboratory bench at $18-20^{\circ} \mathrm{C}$ in natural light and were sub-cultured, if necessary, to eliminate contaminants. A total of 796 single conidium isolates was obtained.
Table 1 The 41 apple orchards in Hawke's Bay (HB), Nelson (Nel), Waikato (Wai) and Central Otago (Ot) from which populations of Venturia inaequalis were isolated during the 2011-2012 season for fungicide sensitivity testing.

\begin{tabular}{|c|c|c|c|}
\hline Orchard no. & $\begin{array}{c}\text { Production } \\
\text { system }^{2}\end{array}$ & Cultivar $^{3}$ & $\begin{array}{c}\text { No. } \\
\text { isolates }\end{array}$ \\
\hline $\begin{array}{l}\text { Hawke's Bay } \\
\text { HB- } 1^{1}\end{array}$ & IFP & RG & 20 \\
\hline $\mathrm{HB}-2^{1}$ & IFP & RG & 20 \\
\hline $\mathrm{HB}-3^{1}$ & IFP & RG & 20 \\
\hline HB-4 & IFP & RG & 20 \\
\hline $\mathrm{HB}-5^{1}$ & Organic & $\mathrm{Br}$ & 20 \\
\hline HB-6 & Organic & $\mathrm{Fu}$ & 20 \\
\hline HB-7 & Organic & PL & 20 \\
\hline HB-8 & Organic & RG & 20 \\
\hline HB-9 & IFP & RG & 20 \\
\hline HB- $10^{1}$ & IFP & RG & 20 \\
\hline HB-11 & IFP & RG & 20 \\
\hline HB-12 & IFP & RG & 20 \\
\hline HB- $13^{1}$ & IFP & RG & 20 \\
\hline HB-14 & IFP & RG & 20 \\
\hline HB- $15^{1}$ & Organic & $\mathrm{Br}$ & 20 \\
\hline HB- $16^{1}$ & IFP & RG & 20 \\
\hline HB-17 & IFP & RG & 20 \\
\hline HB-18 & IFP & RG & 20 \\
\hline HB-19 & IFP & RG & 20 \\
\hline HB-20 & IFP & RG & 20 \\
\hline HB-21 & IFP & RG & 20 \\
\hline HB-22 & IFP & RG & 20 \\
\hline HB-23 & IFP & RG & 14 \\
\hline HB-24 & IFP & RG & 19 \\
\hline HB-25 & IFP & $\mathrm{Fu}$ & 20 \\
\hline \multicolumn{4}{|l|}{ Nelson } \\
\hline $\mathrm{Ne}-01$ & IFP & RG & 8 \\
\hline $\mathrm{Ne}-02$ & IFP & RG & 20 \\
\hline $\mathrm{Ne}-03$ & IFP & RG & 20 \\
\hline $\mathrm{Ne}-04$ & IFP & RG & 19 \\
\hline $\mathrm{Ne}-05$ & IFP & RG & 18 \\
\hline $\mathrm{Ne}-06$ & IFP & RG & 19 \\
\hline $\mathrm{Ne}-07$ & IFP & RG & 19 \\
\hline \multicolumn{4}{|l|}{ Otago } \\
\hline Ot-01 & IFP & RG & 20 \\
\hline Ot-02 & IFP & RG & 20 \\
\hline Ot-03 & IFP & RG & 20 \\
\hline Ot-04 & IFP & RG & 20 \\
\hline \multicolumn{4}{|l|}{ Waikato } \\
\hline Wai-01 & IFP & RG & 20 \\
\hline Wai-02 & IFP & RG & 20 \\
\hline Wai-03 & IFP & RG & 20 \\
\hline Wai-04 & IFP & PL & 20 \\
\hline Wai-05 & IFP & RG & 20 \\
\hline
\end{tabular}

${ }^{1}$ Orchards also sampled in 2010-11 (Beresford et al. 2012).

${ }^{2} \mathrm{IFP}=$ Integrated fruit production.

${ }^{3} \mathrm{RG}=$ 'Royal Gala'; BR='Braeburn'; Fu='Fuji'; $\mathrm{PL}=$ Pink Lady ${ }^{\circledR}$. 


\section{Mycelial growth assay}

Fungicide sensitivity was determined using two discriminatory concentrations of myclobutanil (Systhane $^{\circledR}$ ), penconazole $\left(\right.$ Topas $^{\circledR}$ ) and technical grade dodine (Tables $2 \& 3$ ). The mycelial colony diameter of each isolate was measured on PDA Petri plates amended with each of the two concentrations. These discriminatory concentrations were chosen from the results of the Hawke's Bay survey in 2010-11 (Beresford et al. 2012), based on fungicide concentrations that inhibited growth by $50 \%\left(\mathrm{EC}_{50}\right)$ and the degree of control by these fungicides of disease on apple leaves that were inoculated with resistant isolates. The upper discriminatory concentrations were chosen to be relatively high values that would ensure resistance frequency was not overestimated.

The fungicide-amended plates were inoculated in the centre with an agar disc from the edge of an actively growing colony. Two replicate plates were used for each isolate and fungicide concentration. The Petri plates were incubated for 42 days at 18$20^{\circ} \mathrm{C}$ and two diameters were measured on each plate. Sensitivity of each isolate was expressed as relative growth, which was the mean colony diameter on amended agar as a percentage of the diameter on the non-amended control.

Development of resistance to DMI fungicides generally appears as a quantitative decrease in sensitivity over time, and resistance is a relative term. In this study, isolates with mean relative growth $<50 \%$ of the non-amended control at the lower concentration were classified as sensitive. Isolates with mean relative growth $\geq 50 \%$ of the non-amended control at the lower concentration and $\leq 50 \%$ of the non-amended control at the upper concentration were classified as intermediate sensitivity. Isolates with mean growth at the upper concentration $>50 \%$ of the control were classified as resistant.

\section{Plant inoculation assay}

The ability of five DMI fungicides to control DMI-resistant isolates of $V$. inaequalis was investigated on the leaves of 2-year-old potted 'Gala' apple trees. Shoots were inoculated with either a mixture of three resistant (R) isolates or a mixture of five sensitive (S) isolates (Table 4 ), which had been collected and characterised in the 2010-11 Hawke's Bay orchard survey (Beresford et al.2012). After inoculation, a single spray application was made of eight fungicide treatments. They were (1) fenbuconazole, (2) fenbuconazole plus myclobutanil, (3) flusilazol, (4) difenoconazole, (5) myclobutanil, (6) penconazole, (7) water control (R) and (8) water control (S). Plants receiving treatments 1-7 had been inoculated with $\mathrm{R}$ isolates and those receiving Treatment 8 had been inoculated with $\mathrm{S}$ isolates: A ninth treatment of non-inoculated,

Table 2 Application rates and active ingredient concentration for five demethylation inhibitor (DMI) fungicides contained in six fungicide products registered for use against apple black spot in New Zealand. Systhane ${ }^{\circledR}$ and Topas ${ }^{\circledR}$ were used in the mycelial growth assay to test regional sensitivity of Venturia inaequalis isolates. All six products were used in the plant inoculation assay to investigate black spot control of DMI-resistant isolates.

\begin{tabular}{|c|c|c|c|c|}
\hline $\begin{array}{l}\text { Fungicide active } \\
\text { ingredient (ai) }\end{array}$ & Product & $\begin{array}{l}\text { ai in product } \\
\text { (kg/kg or litre) }\end{array}$ & $\begin{array}{l}\text { Product rate } \\
(\mathrm{g} / \text { litre })^{1}\end{array}$ & $\begin{array}{l}\text { ai rate } \\
(\mathrm{g} / \text { litre })^{1}\end{array}$ \\
\hline Fenbuconazole & Indar ${ }^{\circledR}$ & 0.75 & 0.028 & 0.021 \\
\hline $\begin{array}{l}\text { Fenbuconazole + } \\
\text { Myclobutanil }\end{array}$ & Indar ${ }^{\circledR}$ Duo & $0.75+0.40$ & $0.028+0.090$ & $0.021+0.036$ \\
\hline Flusilazol & Nustar $^{\circledR}$ & 0.20 & 0.150 & 0.030 \\
\hline Difenoconazole & Score $^{\circledR} 10 \mathrm{WG}$ & 0.10 & 0.250 & 0.025 \\
\hline Myclobutanil & Systhane ${ }^{\circledR} 400 \mathrm{WP}$ & 0.40 & 0.120 & 0.048 \\
\hline Penconazole & Topas $^{\circledR}$ 200EW & 0.20 & 0.125 & 0.025 \\
\hline
\end{tabular}

${ }^{1}$ Application rates for the plant inoculation assay 
Table 3 Discriminatory concentrations of myclobutanil, penconazole and dodine used in the mycelial growth assay to determine the regional frequency of fungicide resistance in Venturia inaequalis.

\begin{tabular}{lccc}
\hline Fungicide group & Active ingredient & Lower dose $(\mathrm{mg} /$ litre $)$ & Upper dose $(\mathrm{mg} /$ litre $)$ \\
\hline DMI & Myclobutanil & 0.20 & 1.00 \\
DMI & Penconazole & 0.10 & 0.50 \\
Dodine & Dodine & 0.20 & 1.00 \\
\hline
\end{tabular}

non-fungicide-treated trees was used as a check for background $V$. inaequalis infection. Fungicide product details and application rates are shown in Table 2.

Potted trees with 5-10 leaves per shoot were used for the trial and were inoculated with $1 \times 10^{5} \mathrm{~V}$. inaequalis conidia/ml, comprising equal mixtures of $\mathrm{R}$ or $\mathrm{S}$ isolates. Conidia for inoculation were produced from PDA cultures growing on a cellophane layer to promote sporulation. The youngest unrolled leaf at the time of inoculation was tagged so that inoculated leaves could be identified later. After inoculation, plants were incubated at high relative humidity in a plastic tent for $24 \mathrm{~h}$ and then the fungicide treatments were sprayed to the point of runoff. Six replicate shoots, as two shoots on each of three plants, were used for each treatment. After fungicide treatment, the trees were placed in a glasshouse in a randomised block design for 20 days then the five youngest inoculated leaves on each shoot were visually assessed for percentage of leaf area with sporulating black spot lesions.

\section{Statistical analysis}

Statistical analyses were done using Genstat version 8.1. ANOVA was used to identify significant treatment effects, with mean separation by Tukey's least significant difference (LSD, $\mathrm{P}<0.05$ ). Analysis of fungicide sensitivity used $\log 10 \mathrm{EC}_{50}$ values, rather than $\mathrm{EC}_{50}$ values, to improve normality and variance homogeneity of the data. Disease severity data in the plant inoculation study did not require transformation.

\section{Fungicide usage in the sampled orchards}

Use of DMI and dodine fungicides in the sampled apple blocks was determined from the Pipfruit New Zealand Inc. spray diary database. The numbers of applications of products containing myclobutanil, penconazole, other DMI fungicides and dodine were summarised for five seasons (2007-2008, 2008-2009, 20092010 and 2010-2011 and for the 2011-12 season up to the time the $V$. inaequalis samples were taken). Four of the organic orchards in Hawke's Bay had received no synthetic fungicides for at least 5 years, but organic orchard HB-06 had been under organic management for 3 years and had received synthetic fungicides before that.

\section{RESULTS}

\section{Mycelial growth assay}

The frequency of resistant isolates was higher for myclobutanil than either penconazole or dodine in most orchards from all regions (Figure 1). Every orchard, except for organic orchard HB05 , which had been under organic management for 12 years, had some myclobutanil resistance. The highest myclobutanil resistance frequencies $(\geq 50 \%)$ occurred in three Waikato orchards. These orchards also all had a consistent presence of penconazole resistance, but only two out of the five had dodine resistance. Some of the Hawke's Bay orchards had a relatively high penconazole resistance frequency $(>20 \%)$, particularly HB-19, HB-22 and HB-25. In Otago, the myclobutanil resistance frequency tended to be lower than in other regions and only one Otago orchard had any penconazole resistance (Ot-02). However, all four Otago orchards showed slight dodine resistance. The Nelson orchards had variable myclobutanil resistance and only two out of the seven had any penconazole resistance. One out of the seven had some dodine resistance. Dodine resistance was sporadic in Hawke's Bay, with the organic orchard HB-06 having the highest frequency (40\%). HB-06 also had a high frequency of myclobutanil and penconazole resistant isolates. 
Table $4 \mathrm{EC}_{50}$ (mean fungicide concentration that inhibited mycelial growth by 50\%; mg/litre) for myclobutanil and penconazole for five demethylation inhibitor (DMI)-sensitive and three DMIresistant Venturia inaequalis isolates.

\begin{tabular}{lcccccc}
\hline & Sensitive isolates & & \multicolumn{3}{c}{ Resistant isolates } \\
\cline { 1 - 3 } Isolate & $\begin{array}{c}\mathrm{EC}_{50} \text { to } \\
\text { myclobutanil }\end{array}$ & $\begin{array}{c}\mathrm{EC}_{50} \text { to } \\
\text { penconazole }\end{array}$ & & Isolate & $\begin{array}{c}\mathrm{EC}_{50} \text { to } \\
\text { myclobutanil }\end{array}$ & $\begin{array}{c}\mathrm{EC}_{50} \text { to } \\
\text { penconazole }\end{array}$ \\
\hline 1 & 0.07 & 0.03 & & 6 & 1.49 & 0.94 \\
2 & 0.30 & 0.10 & & 7 & 2.04 & 1.09 \\
3 & 0.12 & 0.08 & & 8 & 1.17 & 0.74 \\
4 & 0.10 & 0.06 & & & & \\
5 & 0.33 & 0.07 & & & & 0.92 \\
\hline Mean & 0.18 & 0.07 & Mean & 1.57 & \\
\hline
\end{tabular}

In relation to the two DMI fungicides, the orchards with a high myclobutanil resistance frequency did not necessarily have a high penconazole resistance frequency. However, for all the individual isolates pooled, the relative growth on myclobutanil and penconazole at the upper discriminatory concentration was highly correlated $(\mathrm{r}=0.70 ; \mathrm{P}<0.001)$, indicating a high degree of cross-resistance between these two DMI fungicides.
Regional means of relative growth provided an indication of the degree of DMI-resistance in individual orchards and summarised the trends in resistance between regions (Figure 2). Waikato orchards had significantly lower sensitivity to both DMIs at both concentrations than orchards in other regions, which did not differ significantly. For dodine, Otago isolates had significantly lower sensitivity at the lower discriminatory concentration than isolates from

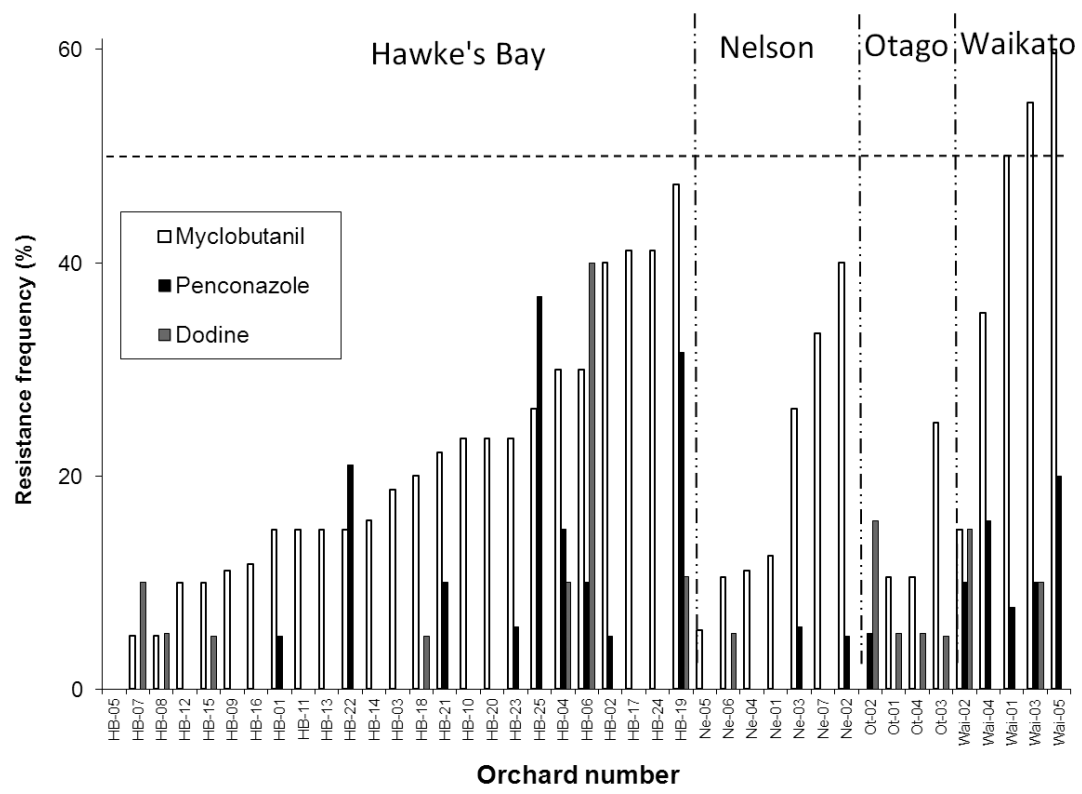

Figure 1 Resistance frequency, as percentage of Venturia inaequalis isolates per apple orchard with $>50 \%$ relative growth at the upper discriminatory concentration of myclobutanil, penconazole or dodine. Forty-one orchards in Hawke's Bay, Nelson, Otago and Waikato, are ranked within each region by myclobutanil resistance frequency. The dotted line indicates a resistance frequency of $50 \%$. 


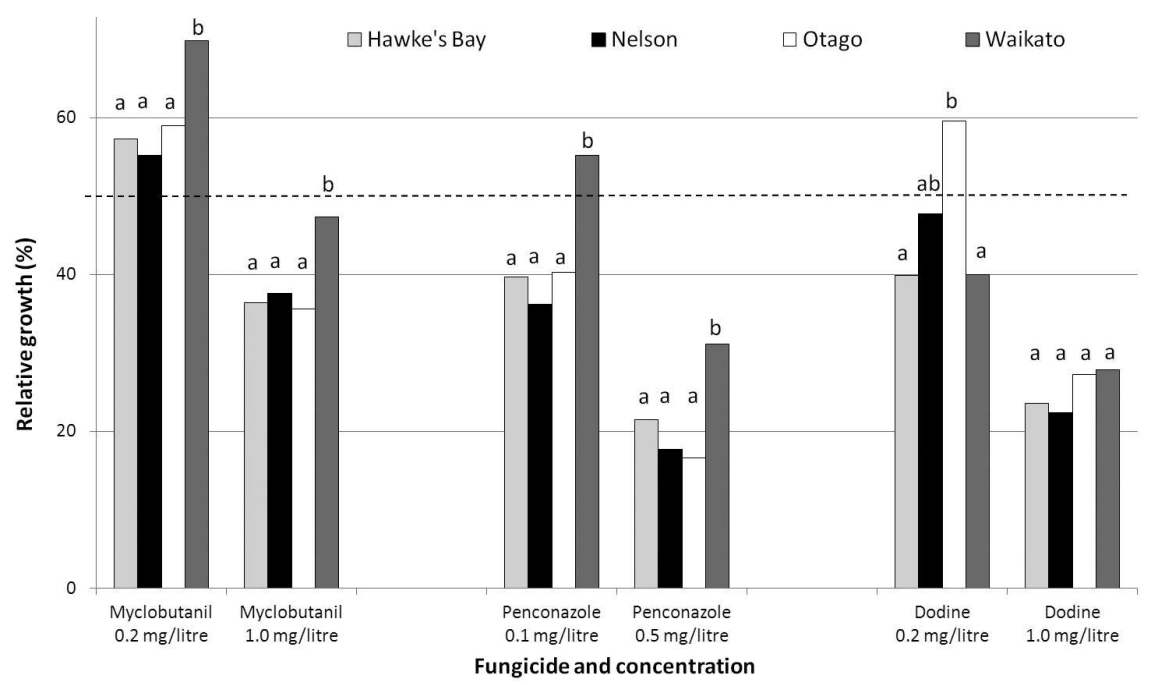

Figure 2 Regional means for relative growth of Venturia inaequalis at two discriminatory concentrations for each of the fungicides myclobutanil, penconazole and dodine from 41 apple orchards in Hawke's Bay, Nelson, Otago and Waikato. Relative growth is the colony diameter after 42 days on fungicideamended agar as a percentage of the non-fungicide-amended control. Bars within each fungicide $\times$ concentration accompanied by the same letter are not significantly different (Tukey's LSD, $\mathrm{P}<0.05$ ).

Hawke's Bay or Waikato, and Nelson isolates were intermediate. There were no significant differences between regions at the upper dodine discriminatory concentration.

\section{Fungicide sensitivity in relation to fungicide usage}

The orchards with the highest resistance frequency to myclobutanil were not necessarily those with the highest DMI use (Figure 1 compared with Figure 3). Waikato orchards, which showed the greatest DMI-resistance, reported relatively low DMI use, which was similar to DMI use in Otago, where DMI resistance frequency was relatively low. The average use of DMIs in Waikato and Otago did not exceed the resistance management guidelines of four applications per season, unlike Hawke's Bay and Nelson, where seven out of 25 $(28 \%)$ and five out of seven $(71 \%)$ of orchards, respectively, had average usage that exceeded the guidelines.

Of the three Hawke's Bay orchards with high penconazole resistance frequency (Figure 1), average DMI use in two exceeded the resistance management guidelines (HB-19, 6.6 applications/ season and HB-25, 7.2 applications/season) and the third was the organic orchard HB-06, with no reported DMI use in the previous five years.

There was no overall correlation between DMI usage and either myclobutanil or penconazole resistance frequency or mean relative mycelial growth at either discriminatory concentration. For orchards that exceeded the DMI resistance management guidelines, there was a significant correlation between penconazole resistance frequency and number of DMI applications per season $(\mathrm{r}=0.35, \mathrm{P}<0.05)$. However, this was driven by orchards HB25 and HB19, which had both high penconazole resistance frequency and high DMI usage.

Although there was no overall correlation between dodine resistance frequency and dodine usage, orchard HB-19, which exceeded the dodine resistance management guidelines, had a relatively high dodine resistance frequency. However, other orchards contradicted this trend, e.g. HB-25, which had no isolates classified as resistant but the highest dodine usage of all orchards, and organic orchard HB-06, which had no dodine usage recorded, but 10\% dodineresistant isolates. 

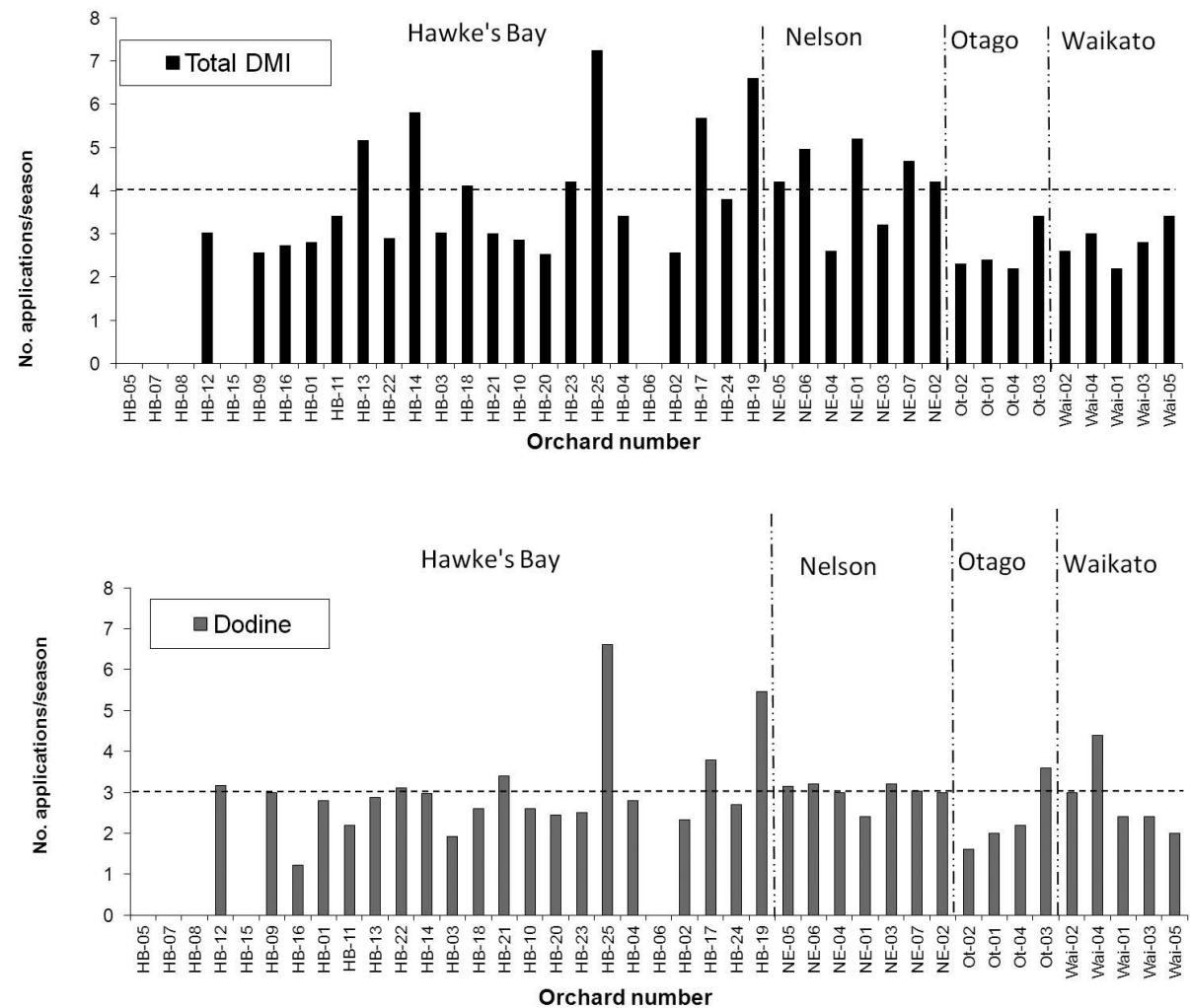

Figure 3 Fungicide usage as mean number of demethylation inhibitor (DMI) or dodine applications per season over five seasons for 41 apple orchards in the 2011-12 resistance survey. Orchards are ranked by frequency of myclobutanil resistance within each region, as for Figure 1. The dotted lines indicate the maximum number of applications per season recommended in resistance management guidelines.

\section{Plant inoculations with DMI-resistant isolates}

The severity of black spot on leaves inoculated with R or Sisolates then treated with different DMI fungicides, or water, fell into in three statistically different groups (Figure 4). These were (a) little or no disease (flusilazol and difenoconazole), (b) intermediate amount of disease (fenbuconazole, fenbuconazole plus myclobutanil, myclobutanil and penconazole) and (c) maximum amount of disease (control trees inoculated with $\mathrm{R}$ or $\mathrm{S}$ isolates and not fungicide-treated). The noninoculated, non-fungicide-treated control trees had zero leaf area affected by black spot at the end of the experiment, indicating there was no background $V$. inaequalis infection.

The trees not treated with fungicide showed no difference in disease between the $\mathrm{R}$ and $\mathrm{S}$ isolates, indicating that both types of isolates were equally capable of causing disease. Although this experiment did not include $S$ isolates treated with the fungicides, it is probable that all the DMI fungicides would have given a high degree of black spot control for sensitive isolates, as had been shown previously (Beresford et al. 2012).

\section{DISCUSSION}

The results of this study, when compared with previous New Zealand and overseas studies (Table 5 ), show that a substantial loss of sensitivity in $V$. inaequalis to DMI fungicides has occurred in all of New Zealand's major apple growing regions. Resistance to myclobutanil is very widespread and although resistance to penconazole was at a lower frequency, it was also present in many orchards. Waikato was the region with the greatest DMI resistance frequency. Although 


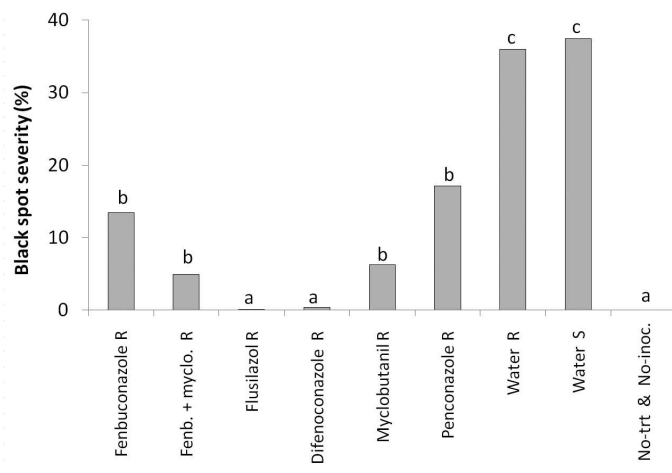

Figure 4 Black spot severity as mean percentage of leaf area affected on potted apple plants inoculated with Venturia inaequalis isolates that were either resistant (R) or sensitive (S) to demethylation inhibitor fungicides and then sprayed with eight fungicide treatments. Background infection was checked using the not-inoculated, no-fungicide treatment. Means accompanied by the same letter are not significantly different (LSD P $<0.05$ ).

this region has a high climatic risk of black spot, requiring intensive fungicide spray programmes, the high resistance frequency was not able to be correlated with 5-year DMI fungicide usage from the orchard spray diaries. There was a generally low correlation between DMI fungicide usage and muclobutanil or penconazole resistance in each region. This could be the result of representational error because of the relatively small $V$. inaequalis sample population from each orchard (20 isolates). It could also be the result of spray diary inaccuracy or inaccurate matching between spray diary records and the orchard areas actually sampled for $V$. inaequalis.

Only one orchard had no DMI resistant isolates: HB-05 had been in organic production with no DMI use for 12 years. Most of the other organic orchards also had low DMI resistance frequency, except HB06, which had been under organic production for only 3 years and was known to have had DMI and dodine applications prior to organic conversion. The widespread occurrence of myclobutanil resistance, even in some organic orchards, and the lack of correlation with 5-year DMI fungicide usage suggests that myclobutanil resistance has been developing over a wide area for a long period.

The plant inoculation assay showed that for DMI-resistant strains of $V$. inaequalis, myclobutanil, penconazole and fenbuconazole gave lower disease control than the newer DMI active ingredients, flusilazol and difenoconazole. This has also been reported overseas (Rosenberger \& Cox 2010). The product mixture containing both fenbuconazole and myclobutanil did not significantly improve disease control over either one of the active ingredients alone. While $V$. inaequalis is presumed to be cross resistant to all five DMI active ingredients, flusilazol and difenoconazole would be expected to provide more effective black spot control for the $V$. inaequalis strains currently present in New Zealand orchards than muclobutanil, penconazole or fenbuconazole. However, despite the presence of resistant isolates, myclobutanil could still be expected to give disease control in orchards where the frequency of DMI-resistant isolates is low.

The upper discriminatory myclobutanil concentration chosen for this study to classify $V$. inaequalis isolates as resistant was high compared with the discriminatory doses that are generally used (Russell 2002). Köller et al. (1997) and Rosenberger \& Cox (2010) reported a discriminatory myclobutanil dose of $0.1 \mathrm{mg} /$ litre in the USA and Canada, which was slightly lower than the lower discriminatory concentration used in the present study to identify sensitive isolates. The upper discriminatory concentration used in the present study was derived from agar-based $\mathrm{EC}_{50}$ values that were shown to be associated with lack of disease control on inoculated and DMI-treated apple plants. Discriminatory doses in other studies have been derived from shifts in sensitivity on agar above a baseline, sometimes without reference to actual disease control. DMI resistance is quantitative and even the isolates identified in this study as DMI-resistant at the upper discriminatory concentration on agar were partially controlled by both myclobutanil and penconazole. The high concentration thresholds for defining resistance 
Table 5 Comparative values for the mean fungicide concentration that inhibits growth of Venturia inaequalis by $50 \%\left(\mathrm{EC}_{50}\right.$ ) for two demethylation inhibitor (DMI) fungicides (myclobutanil and penconazole) and for dodine.

\begin{tabular}{lccccc}
\hline & Year & & \multicolumn{3}{c}{ EC $_{50}(\mathrm{mg} /$ litre $)$} \\
\cline { 4 - 6 } Reference & surveyed & Geography & Myclobutanil & Penconazole & Dodine \\
\hline Köller \& Wilcox $(1999)^{1}$ & $1970 s$ & USA \& Canada & - & - & 0.2 \\
Köller et al. $(1991)^{2}$ & ca 1990 & NY State, USA & 0.07 & 0.03 & - \\
Jobin \& Carisse $(2007)^{3}$ & 2003 & Quebec & 0.064 & - & - \\
Jobin \& Carisse $(2007)^{4}$ & 2003 & Quebec & $1.5-3.1$ & - & - \\
Whelan et al. $(1992)^{2}$ & $1990-91$ & NZ & 0.16 & 0.039 & - \\
Bakker et al. $(1995)^{2}$ & $1993-94$ & NZ & 0.43 & 0.10 & 0.85 \\
Bakker (1999) & $1997-98$ & NZ & - & - & 0.527 \\
Beresford et al. $(2012)^{2}$ & $2010-11$ & Hawke's Bay, NZ & 0.69 & 0.12 & 0.24 \\
This study & $2011-12$ & NZ & 0.59 & 0.11 & 0.25 \\
\hline
\end{tabular}

${ }^{1}$ Discrimatory dose to detect sensitive isolates.

${ }^{2}$ Baseline sensitivity.

${ }^{3}$ Commercial orchards.

${ }^{4}$ Commercial orchards with disease control failure.

${ }^{5}$ Estimated from relative growth at two concentrations in this study and $\mathrm{EC}_{50}$ values from Beresford (2012).

in the present study are likely to relate well to practical resistance (Köller et al. 1997) associated with disease control problems in the field. Use of too low a discriminatory dose runs the risk of overestimating resistance frequency with respect to loss of disease control. In relation to detecting penconazole resistance in this study, it is possible that the relatively low frequency of resistant isolates in orchards determined by the mycelial growth assay, yet the poor control of resistant isolates on potted plants, may indicate that the upper discriminatory penconazole concentration was too high.

Dodine resistance in $V$. inaequalis does not appear to be a problem in New Zealand apple orchards, although it was present in all regions, particularly Otago. The present study confirmed the Hawke's Bay data from 2010-11 (Beresford et al. 2012) that dodine sensitivity has not increased since the 1990s and may have actually decreased (Table 4). Given the widespread resistance to dodine found overseas (Chapman et al. 2011), it suggests that the relatively conservative resistance management guideline in New Zealand of three applications per season is helping to reduce dodine resistance development. Overseas, dodine resistance was reported to decline significantly after 4 years (Michigan) or 13 years (NY State) of no dodine use after a serious resistance problem had previously been reported (Köller \& Wilcox 1999).

The Pipfruit New Zealand Inc. spray diary data showed that there were many instances where resistance guidelines were exceeded, especially for DMIs. Continued adherence to the New Zealand resistance management guidelines is essential and these guidelines are being updated by the New Zealand Committee on Pesticide Resistance (Beresford et al. 2009) to accommodate the new findings from this study.

\section{ACKNOWLEDGEMENTS}

We would like to thank the apple growers in Hawke's Bay, Waikato, Nelson and Otago who allowed black spot sampling in their orchards and Dr Mike Butcher of Pipfruit New Zealand, for reviewing a draft of this paper. This project was funded by Pipfruit New Zealand Inc., Plant \& Food Research, Adria Crop Protection Ltd, BASF New Zealand, Zelam Ltd, Bayer CropScience, Dow Agrosciences, PGG Wrightson and Syngenta Crop Protection. 


\section{REFERENCES}

Bakker GR 1999. Sensitivity of Venturia inaequalis and $V$. pirina to dodine in New Zealand. Proceedings of the $52^{\text {nd }}$ New Zealand Plant Protection Conference: 167-170.

Bakker GR, Butcher MR, Gaunt RE 1995. Sensitivity of apple black spot to fenarimol, flusilazol, myclobutanil, penconazole and dodine in New Zealand. Proceedings of the $48^{\text {th }}$ New Zealand Plant Protection Conference: 7-11.

Beresford RM 2005a. DMI (demethylation inhibitor) management strategy. In: Martin NA, Beresford RM, Harrington KC ed. Pesticide resistance: prevention and management strategies 2005. Hastings, New Zealand Plant Protection Society Inc. Pp. 2125.

Beresford RM 2005b. Dodine management strategy. In: Martin NA, Beresford RM, Harrington KC ed. Pesticide resistance: prevention and management strategies 2005. Hastings, New Zealand Plant Protection Society Inc. Pp. 27-28.

Beresford RM, Follas GB, Hagerty GC, Harrington KC, Martin NA 2009. The New Zealand Committee on Pesticide Resistance (NZCPR). New Zealand Plant Protection 62: 393-394.

Beresford RM, Wright PJ, Wood PN, Park NM 2012. Sensitivity of Venturia inaequalis to myclobutanil, penconazole and dodine in relation to fungicide use in Hawke's Bay apple orchards. New Zealand Plant Protection 65: 106-113.

Chapman KS, Sundin GW, Beckerman JL 2011. Identification of resistance to multiple fungicides in field populations of Venturia inaequalis. Plant Disease 95: 921-926.

FRAC 2013. Fungicide Resistance Action Committee. www.frac.info/publication/ anhang/FRAC $\% 20$ Code $\% 20$ List $\% 20$ 2013-final.pdf (accessed 14 April 2013).
Jobin T, Carisse O 2007. Incidence of myclobutanil- and kresoxym-methylinsensitive isolates of Venturia inaequalis in Quebec orchards. Plant Disease 91: 13511358.

Köller W, Parker DM, Reynolds KL 1991. Baseline sensitivities of Venturia inaequalis to sterol demethylation inhibitors. Plant Disease 75: 726-728.

Köller W, Wilcox WF, Barnard J, Jones AL, Braun PG 1997. Detection and quantification of resistance of Venturia inaequalis to sterol demethylation inhibitors. Phytopathology 87: 184-190.

Köller W, Wilcox WF 1999. Evaluation of tactics for managing resistance of Venturia inaequalis to sterol demethylation inhibitors. Plant Disease 83: 857-863.

Larsen NJ, Beresford RM, Wood PN, Wright PJ, Fisher BM 2013. A synthetic agar assay for determining sensitivity of Venturia inaequalis to anilinopyrimidine fungicides in New Zealand apple orchards. New Zealand Plant Protection 66: 293-302.

Rosenberger DA, Cox KD 2010. Apple scab management options for high-inoculum orchards. New York Fruit Quarterly 18(1): 3-8.

Russell PE 2002. Sensitivity baselines in fungicide resistance research and management. FRAC monograph No.3. AIMPRINT, UK. 56 p.

Viljanen-Rollinson SLH, Thompson S, Keenan S, Bulman S, Wright PJ, Wood PN, Park NM, Beresford RM 2013. Sensitivity to QoI fungicides in New Zealand isolates of Venturia inaequalis. New Zealand Plant Protection 66: 284-292.

Whelan HG, Butcher MR Gaunt RE 1992. Sensitivity of Venturia inaequalis (black spot) on apples to DMI fungicides in New Zealand. Proceedings of the $45^{\text {th }}$ New Zealand Plant Protection Conference: 289-294. 